\title{
BMP7 coordinates endometrial epithelial cell receptivity for blastocyst implantation through the endoglin pathway in cell lines and a mouse model
}

\author{
CAIXIA YUAN ${ }^{1,2}$, XIANLIAN LI ${ }^{2}$, HAIXIA SONG ${ }^{2}$, LINGLING FAN ${ }^{2}$, \\ SHILI SU ${ }^{1}$ and BAIHUA DONG ${ }^{1}$ \\ ${ }^{1}$ Department of Gynecology and Obstetrics, Qilu Hospital, Shandong University, \\ Jinan, Shandong 250012; ${ }^{2}$ Department of Reproductive Medicine, \\ Shanxi Provincial People's Hospital, Taiyuan, Shanxi 030012, P.R. China
}

Received May 14, 2018; Accepted January 16, 2019

DOI: $10.3892 /$ etm.2019.7265

\begin{abstract}
Bone morphogenetic protein (BMP) expression has been observed in the uterus in previous studies. However, the influence of BMP7 on blastocyst implantation remains unclear. Blastocysts first act on luminal endometrial epithelial cells during implantation. The purpose of the present study was to explore the influence of BMP7 on endometrial epithelial cells. A pregnancy animal model, and mouse and human endometrial epithelial cells were used in the present study. Transient knockdown, immunofluorescence assay, in vitro embryo implantation, BMP7 silencing, reverse transcription-quantitative polymerase chain reaction, western blotting, immunoprecipitation and Racl function assay were also performed. It was revealed that BMP7 concentration was increased in endometrial epithelial cells during the final pre-receptive and receptive stages of receptivity in the mouse endometrium. Additionally, BM7 acted on the transforming growth factor- $\beta$ receptor, endoglin. Endoglin expression was detected in both stromal and endothelial cells apart from trophoblast expression. Following knockdown of BMP7, Rac-GTP was decreased in endometrial epithelial cells and the uterus. Knockdown of endoglin by small interfering RNA decreased the number of blastocysts and implantation regions. Additionally, BMP7 silencing and endoglin suppression of Ishikawa cells led to impaired JAr spheroid attachment. These findings suggest that BMP7 is associated with receptivity of the endometrium, indicating that BMP7 regulates receptivity of endometrial epithelial cells for implantation of blastocysts via the endoglin pathway.
\end{abstract}

Correspondence to: Dr Baihua Dong, Department of Gynecology and Obstetrics, Qilu Hospital, Shandong University, 107 West Wenhua Road, Jinan, Shandong 250012, P.R. China

E-mail: dongbaihua01@163.com

Key words: bone morphogenic protein 7, endometrial epithelial cell, receptivity, blastocyst implantation, endoglin

\section{Introduction}

The window of endometrial receptivity is essential in the implantation of blastocysts and triggers multiple reactions arising from the endometrium as well as blastocysts (1). The reaction is complex and the receptive endometrium or uterus are closely associated with the stimulated/competent/implanting blastocysts (2). The receptive endometrium and stimulated blastocysts simultaneous function to achieve blastocyst implantation, leading to pregnancy (3).

Mouse blastocyst implantation occurs in a series of pre-receptive [day $4(1000 \mathrm{~h})$ ], early receptive [day 4 (1600 h)], receptive [day $5(0500 \mathrm{~h})$ ] and refractory [day $5(1000 \mathrm{~h})$ ] periods (4). Regardless of the species, interactions between the uterus and developing conceptus occur during the endometrial receptive period. The uterine condition must be conducive to assisting in implantation and development of the embryo to establish pregnancy (5). Cytokines, steroid hormones, peptides, growth factors and enzymes are essential for implantation (6).

The transforming growth factor (TGF) $\beta$ family has been highly conserved throughout evolution and consists of secreted elements that modulate developmental reactions including proliferation and differentiation $(7,8)$. Bone morphogenetic protein (BMP) belongs to the TGF- $\beta$ family and binds to receptor complexes made up of two BMP type 1 receptors [activin receptor-like kinase (ALK)6, ALK3 or ALK2] and two type 2 receptors [activin A receptor type (ACVR2) B, ACVR2A or BMP receptor (BMPR) 2] (9). Following BMP binding, mothers against decapentaplegic homolog (SMAD)5 and/or SMAD1 are phosphorylated, which was demonstrated to be associated with SMAD4 (10). These proteins are then translocated to the nucleus to regulate the expression of specific genes depending on the context. The BMP pathway participates in modulating the implantation of blastocysts, endometrial epithelial cells decidualization, and placenta development (11). BMP2 and its corresponding receptor ALK2 are indispensable to the fertility of females. Conditional deletion of BMP2 and ALK2 inhibits endometrial epithelial cell decidualization (7). BMPR2 deletion in the female reproductive tract leads to development-retarded embryos, aberrant generation of uterine vessels, and limited 
placental development. However, the influence of BMP7 on the female reproductive tract as well as the potential additional effects of BMP7 and BMP5 has not been examined.

Endoglin is a type 1 transmembrane glycoprotein, which serves as an assisted TGF- $\beta$ receptor and causes phosphorylation of downstream factors including Smad transcription factor family members (12). Type 1 and 2 TGF- $\beta$ receptors act on type 3 co-receptors such as endoglin, although the understanding of endoglin activity inside or outside receptor complexes is insufficient $(13,14)$. Endoglin expression mainly occurs in the proliferating endothelium, stroma and placental syncytiotrophoblasts (15).

Although previous studies have demonstrated that endoglin is present in the uterine stroma and endothelium, its effect on uterine receptivity in terms of embryo implantation remains unclear. Previous studies also demonstrated that BMP7 is expressed in the endometrium during the early stages of pregnancy. However, the role of BMP7 in the blastocyst implantation has not been assessed. In the current study, the authors demonstrated that endoglin was stimulated by Racl signaling in reaction to BMP7 and endoglin signaling occurred in endometrial epithelial cells during the acquisition of endometrial epithelial cell receptivity to establish embryo implantation.

\section{Materials and methods}

Antibodies and reagents. Progesterone, 17- $\beta$-estradiol, collagenase type II, non-essential amino acids, propidium iodide, minimum essential medium Eagle, sodium bicarbonate, phosphatase inhibitor, protease inhibitor cocktail, anti-BMP7 (1:1,000; cat. no. SAB1403611), anti-RAC1 (1:1,000; cat. no. SAB4300461), anti-endoglin (1:1,000; cat. no. SRP6015), and anti-actin (1:4,000; cat. no. A5441) antibodies were all obtained from Sigma-Aldrich; Merck KGaA (Darmstadt, Germany).

Pregnancy animal model. A total of 4 wild-type female Swiss albino mice (age, 6-8 weeks; weight, 22 g) were purchased from Beijing Vital River Laboratory Animal Technology Co., Ltd. (Beijing, China). Mice were kept in a chamber in a room with controlled temperature $\left(20-23^{\circ} \mathrm{C}\right)$ under a 12 -h light/dark cycle with relative humidity (40-60\%). Mice were given water and food ad libitum. The present study was approved by the Ethics Committee of Qilu Hospital, Shandong University (Jinan, China). Mice were sacrificed on different days of embryo implantation, i. e., day 4 (1000 h; prior to implantation), day 4 (1600 h; final stage prior to implantation), day 5 (0500 h; around implantation) and day 5 (1000 h; following implantation), and uterine specimens were obtained. Embryos were examined under a light microscope (NIKON ECLIPSE-801; Nikon Corporation, Tokyo, Japan) to confirm the different periods of receptivity and different stages of endometrial receptivity for embryo implantation by the presence of morula, blastocyst, hatched blastocyst and implanting blastocyst stages, as previously described (16). Strips of uterine tissue $(\sim 2 \times 5 \mathrm{~mm})$ were obtained from the mesometrium between placental discs as previously described and used in subsequent experimentation $(17,18)$.

Mouse endometrial epithelial cells isolation, cell culture, and transient knockdown assay. Fat and connective tissues were removed by washing with phosphate-buffered saline, and the uterus was cut longitudinally into small pieces. The uteri pieces were incubated in PBS containing collagenase type 2 and $0.1 \%$ dispase-2 (both Sigma-Aldrich; Merck KGaA) for $10 \mathrm{~min}$ at $37^{\circ} \mathrm{C}$. The supernatant was added to a $15-\mathrm{ml}$ tube containing $2 \mathrm{ml}$ fetal bovine serum (FBS; Sigma-Aldrich; Merck KGaA), with 4 tubes for each sample. Subsequently, the supernatant was centrifuged for at $400 \mathrm{xg}$ for $5 \mathrm{~min}$ at $4^{\circ} \mathrm{C}$. Epithelial cells were obtained using the EasySep ${ }^{\mathrm{TM}}$ Mouse Epithelial Cell Enrichment kits (Stemcell Technologies, Inc., Vancouver, BC, Canada), according to the manufacturer's protocol. Briefly, mice endometrial epithelial cells were harvested and grown in 1\% Dulbecco's modified Eagle's medium (DMEM; Invitrogen; Thermo Fisher Scientific, Inc., Waltham, MA, USA) supplemented with $10 \% \mathrm{FBS}$ and $100 \mathrm{U} / \mathrm{ml}$ penicillin/streptomycin (Gibco; Thermo Fisher Scientific, Inc.) at $37^{\circ} \mathrm{C}$; this time point was defined as $0 \mathrm{~h}$. Following 12-h incubation, transient BMP7 knockdown was performed using small interfering (si)RNA targeting BMP7 (Thermo Fisher Scientific, Inc.). Briefly, cells were serum starved for $4 \mathrm{~h}$ at $37^{\circ} \mathrm{C}$ prior to 12 -h transfection with 200 pmol BMP7 siRNA (5'-CAGCCGAATTCCGGA TCT-3') in Opti-MEM ${ }^{\circledR}$ (Gibco; Thermo Fisher Scientific, Inc.) using Lipofectamine ${ }^{\circledR} 2000$ (Invitrogen; Thermo Fisher Scientific, Inc.). The medium was changed to DMEM supplemented with $10 \%$ FBS and $100 \mathrm{U} / \mathrm{ml}$ penicillin/streptomycin and cells were maintained at $37^{\circ} \mathrm{C}$ for $12 \mathrm{~h}$.

Immunofluorescence. Mouse endometrial epithelial cells were seeded at a density of $2 \times 10^{6}$ cells/well into six-well plates, with each well containing sterile coverslips. Following $24 \mathrm{~h}$ growth, $4 \%$ paraformaldehyde in PBS was used to fix cells for $20 \mathrm{~min}$ at $37^{\circ} \mathrm{C}$. Cells were washed with PBS and subsequently permeabilized with PBS containing $1 \%$ bovine serum albumin (BSA; Sigma-Aldrich; Merck KGaA) and 0.2\% Triton X-100 for $20 \mathrm{~min}$ at room temperature. Cells were blocked for $2 \mathrm{~h}$ at room temperature with $1 \%$ BSA in PBS followed by washing with PBS. Cells were incubated with anti-cytokeratin pan-fluorescein isothiocyanate (1:1,000; F3418; Sigma-Aldrich; Merck $\mathrm{KGaA}$ ) overnight at $4^{\circ} \mathrm{C}$. Cells were washed with PBS three times and nuclei were stained with DAPI $(1 \mu \mathrm{g} / \mathrm{ml})$ for $1 \mathrm{~min}$ at room temperature. Subsequently $70 \%$ glycerol was utilized to place coverslips on the slides and cells were imaged using a laser scanning confocal microscope (magnification, x100).

BMP7 and endoglin siRNA transfection of human endometrial cells. Ishiwaka cells, a human endometrial adenocarcinoma cell line was purchased from Sigma-Aldrich; Merck KGaA. Ishiwaka cells were cultured in minimum essential medium Eagle (MEM; Sigma-Aldrich; Merck KGaA) supplemented with $10 \% \mathrm{FBS}$ and maintained at $37^{\circ} \mathrm{C}$ in a $5 \% \mathrm{CO}_{2}$ humidified incubator. Human choriocarcinoma cells JAr was purchased from the American Type Culture Collection (Manassas, VA, USA). JAr cells were cultured in DMEM/F12 supplemented with $10 \%$ FBS, $1 \%$ antibiotics and antimycotics (100X; Thermo Fisher Scientific, Inc.) and maintained at $37^{\circ} \mathrm{C}$ in a $5 \% \mathrm{CO}_{2}$-humidified incubator.

JAr cells were seeded into non-adherent 96-well plates at density of $1 \times 10^{4}$ cells/well, which facilitated the cultivation of homogenous cellular aggregates with high performance efficiencies in parallel. The size can be controlled by the initial cell density per well. Ishikawa cells were seeded into 12 -well plates 
at density of $1 \times 10^{4}$ cells/well and incubated at $37^{\circ} \mathrm{C}$ for $12 \mathrm{~h}$ in a $5 \% \mathrm{CO}_{2}$-humidified incubator. A total of $1 \mu \mathrm{l} \mathrm{BMP7} \mathrm{(5'-CAG}$ CCGAATTCCGGATCT-3') or endoglin (5'-UGACCUGUC UGGUUGCACATT-3') siRNA (50 ng/ $\mu \mathrm{l})$ was diluted in $50 \mu \mathrm{l}$ Opti-MEM ${ }^{\circledR}$ in microcentrifuge tubes with no RNase; and $1 \mu \mathrm{l}$ of Lipofectamine ${ }^{\circledR} 2000$ was diluted in $50 \mu$ Opti-MEM $^{\circledR}$ in microcentrifuge tubes were incubated for $20 \mathrm{~min}$ at room temperature. The Opti-MEM ${ }^{\circledR}$-siRNA and Lipofectamine ${ }^{\circledR}$ 2000-Opti-MEM ${ }^{\circledR}$ suspension were mixed and incubated for an additional $30 \mathrm{~min}$ at room temperature, and then added to the wells containing serum-free media $(900 \mu \mathrm{l})$. The cells were then incubated at $37^{\circ} \mathrm{C}$ in a $5 \% \mathrm{CO}_{2}$-humidified incubator for $12 \mathrm{~h}$. Cells were grown at $37^{\circ} \mathrm{C}$ in complete media for an additional $12 \mathrm{~h}$.

In vitro embryo implantation. JAr cells were incubated in DMEM/F12 supplemented with $10 \%$ FBS, $1 \%$ antibiotics and antimycotics (100X; Thermo Fisher Scientific, Inc.) for $12 \mathrm{~h}$ on a shaker at $200 \mathrm{rpm}$ at $37^{\circ} \mathrm{C}$ in a $5 \% \mathrm{CO}_{2}$-humidified incubator. The first filtration was carried out using a $100-\mu \mathrm{m}$ membrane, whilst the second filtration was carried out using a 70- $\mu \mathrm{m}$ membrane to obtain 70-100 $\mu \mathrm{m}$ spheroids. Samples were incubated with Cell Tracker Red CMTPX (cat. no. C34552; Thermo Fisher Scientific, Inc.) for $10 \mathrm{~min}$ at room temperature. Spheroids were resuspended in phenol red-free media (cat. no. 2104025; Thermo Fisher Scientific, Inc.). A 10-min co-culture of spheroids was carried out in the presence of endoglin siRNA, BMP7 siRNA or control siRNA (Santa Cruz Biotechnology, Inc., Dallas, TX, USA) at room temperature prior to washing with DMEM. Spheroid attachment was assessed under a light microscope.

Intraluminal Morpholino oligonucleotide (MO) delivery for endometrial BMP7 silencing. Antisense MO sequences targeting mouse BMP7 were designed and provided by Gene Tools, LLC (Philomath, OR, USA) and used to knockdown BMP7 in mice. Gravid mice received laparotomy under local anesthesia and narcosis on the fourth day $(1000 \mathrm{~h})$ of the receptivity period to inject BMP7 MO (5'-CTGTTTTACTTACGA AACTGTCATT-3'; Gene Tools, LLC) into one of the uterine horns. The remaining uterine horn was treated with control MO (5'-CCTCTTACCTCAGTTACAATTTAT-3'; Gene Tools, LLC, USA). Evans blue dye (100\%) was injected into mice prior to being sacrifice on the fifth day (1000 h) to examine the location of embryo implantation. Images of the uterus were captured to assess embryo implantation using a light microscope (magnification, $\mathrm{x} 40$ ).

Reverse transcription-quantitative polymerase chain reaction (RT-qPCR). Total RNA was extracted from uteri tissue using TRIzol $^{\circledR}$ reagent (Invitrogen; Thermo Fisher Scientific, Inc.). RNA $(1 \mu \mathrm{g})$ was reverse transcribed into cDNA using the SuperScript III kit (Thermo Fisher Scientific, Inc.), according to the manufacturer's protocol. PCR samples for each specimen contained cDNA, PCR Super Mix (Thermo Fisher Scientific, Inc.) and forward and reverse primers (20 pmol). qPCR was subsequently performed in triplicate using the SYBR Premix Ex Taq (Takara Biotechnology Co., Ltd., Dalian, China) and SsoFast $^{\mathrm{TM}}$ Probes Supermix (Bio-Rad Laboratories, Inc., Hercules, CA, USA) and a standard thermocycling procedure was performed on a Bio-Rad CFX96 ${ }^{\mathrm{TM}}$ Real-time PCR System (Bio-Rad Laboratories, Inc.). The following primer pairs listed were used for qPCR: Bmp7 forward, 5'-GGATTTTTAGGT TTGTTGGTTG-3' and reverse, 5'-CAACTCACAATAAAC ACACATACAT-3'; endoglin, forward, 5'-GCCgGCTTGTCT CCTTCATG-3' and reverse, 5'-GCAACAAGCTCTTTCTTT AGTACCA-3'; and $\beta$-actin forward, 5'-AAATCTGGCACC ACACCTTC-3' and reverse, 5'-GGGGTGTTGAAGGTCT CAAA-3'.

The following thermocycling conditions were used for the qPCR: Initial denaturation at $95^{\circ} \mathrm{C}$ for $1 \mathrm{~min} ; 38$ cycles of $95^{\circ} \mathrm{C}$ for $1 \mathrm{~min}, 57^{\circ} \mathrm{C}$ for $1 \mathrm{~min}, 72^{\circ} \mathrm{C}$ for $1 \mathrm{~min}$; and a terminal extension at $72^{\circ} \mathrm{C}$ for $10 \mathrm{~min}$. The $2^{-\Delta \Delta \mathrm{Cq}}$ method (19) was used to analyze the relative changes in gene expression and normalized to the internal reference gene $\beta$-actin.

Protein extraction. Uterine tissue samples were washed with washing buffer [100 mM KCl (pH 7.4), $3.5 \mathrm{mM} \mathrm{MgCl}_{2}$, protease and phosphatase inhibitor cocktail, $3 \mathrm{mM} \mathrm{NaCl}$ and $10 \mathrm{mM}$ PIPES] was used for uterine tissue washing. Following homogenization, tissues were centrifuged at $200 \mathrm{x}$ g for $15 \mathrm{~min}$ at $4^{\circ} \mathrm{C}$. The supernatant was removed and centrifuged for $10 \mathrm{~min}$ at $1,500 \mathrm{x} \mathrm{g}$ at $4^{\circ} \mathrm{C}$. The acquired post-nuclear supernatant was further centrifuged at $12,000 \mathrm{x} \mathrm{g}$ for $10 \mathrm{~min}$ at $4^{\circ} \mathrm{C}$. The harvested post-mitochondrial supernatant served as raw protein extract linked to cytosol and mitochondrial membranes and were stored at $-80^{\circ} \mathrm{C}$. Total protein was extracted from Ishiwaka cell lysates and separated primary epithelium using radioimmunoprecipitation assay buffer $(25 \mathrm{mM}$ Tris, $150 \mathrm{mM}$ $\mathrm{NaCl}, 0.1 \%$ SDS, $0.5 \%$ sodium deoxycholate, $1 \%$ Triton $\mathrm{X}-100$ ). Total protein was quantified using the Pierce BCA Protein Assay kit (Thermo Fisher Scientific, Inc.).

Immunoprecipitation. Protein A-Agarose (Invitrogen; Thermo Fisher Scientific, Inc.) was used for preliminary elimination of protein extracts obtained at various receptivity periods. Protein extracts $(100 \mu \mathrm{g})$ mixed with protein A-Agarose were incubated with anti-BMP7 antibody (1:100) overnight at $4^{\circ} \mathrm{C}$. Protein A-Agarose was washed with PBS and a Protein A-Agarose slurry was prepared using cytosolic buffers. Protein complexes were captured on Protein A-Agarose at $4{ }^{\circ} \mathrm{C}$ for $2 \mathrm{~h}$. Subsequently, $10 \%$ SDS-PAGE was applied to resolve proteins for western blotting.

Western blotting. Laemmli sample buffer containing $2.5 \% \beta$-mercaptoethanol (Sigma-Aldrich; Merck KGaA) was used for protein denaturation. Denatured protein $(20 \mu \mathrm{g}$ protein/lane) were separated via SDS-PAGE on a $10 \%$ gel. The separated proteins were transferred to polyvinylidene difluoride membranes and blocked at room temperature for $1 \mathrm{~h}$ with $5 \%$ skimmed milk. Membranes were incubated with primary antibodies $(1: 1,000)$ overnight at $4^{\circ} \mathrm{C}$. Following primary incubation, membranes were incubated with horseradish peroxidase (HRP)-conjugated secondary antibodies (anti-mouse, AP192P; 1:4,000 and anti-rabbit, AP182P 1:4,000; both Sigma-Aldrich; Merck $\mathrm{KGaA}$ ) at $25^{\circ} \mathrm{C}$ for $1 \mathrm{~h}$. The membranes were washed with Tris buffered-saline containing $0.1 \%$ Tween ${ }^{\circledR} 20$ and protein bands were visualized using the Immobilon Western Chemiluminescent HSP Substrate (cat. no. WBKLS0500; EMD Millipore, Billerica, MA, USA). Protein expression was quantified using Total Lab Quant 1D gel analysis software (version 5.01; Nonlinear Dynamics, Ltd., Newcastle, UK). 
A
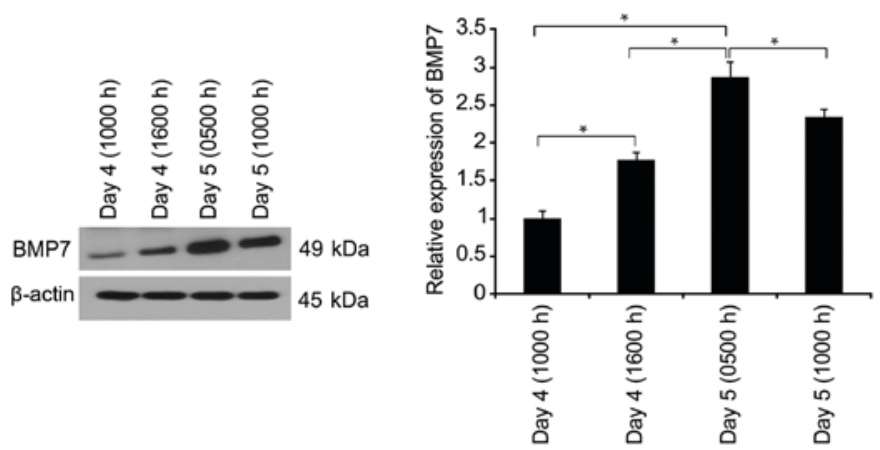

B
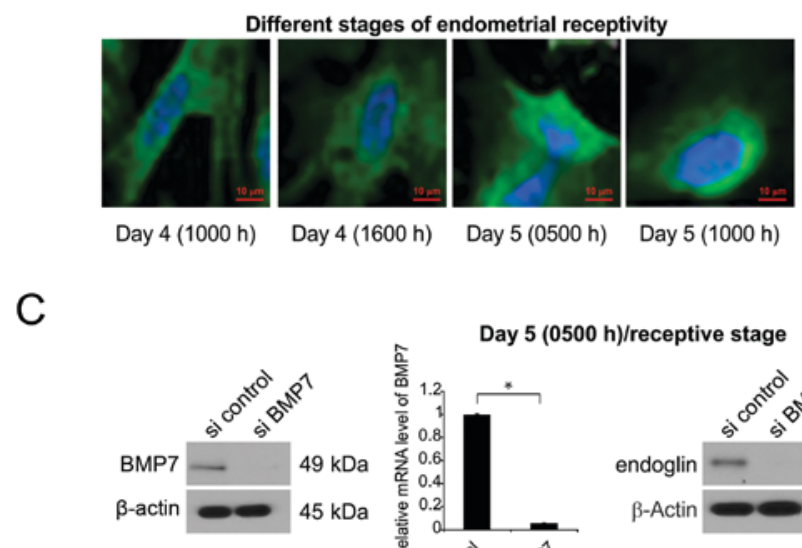

D

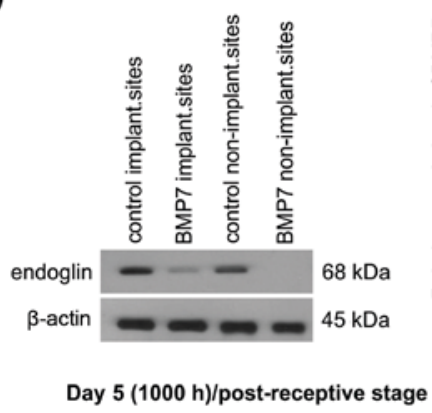

Day $5(0500 \mathrm{~h}) /$ receptive stage

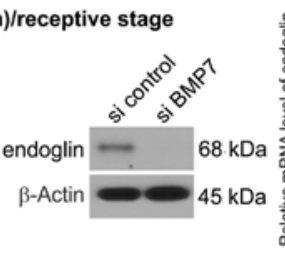

$\mathrm{E}$
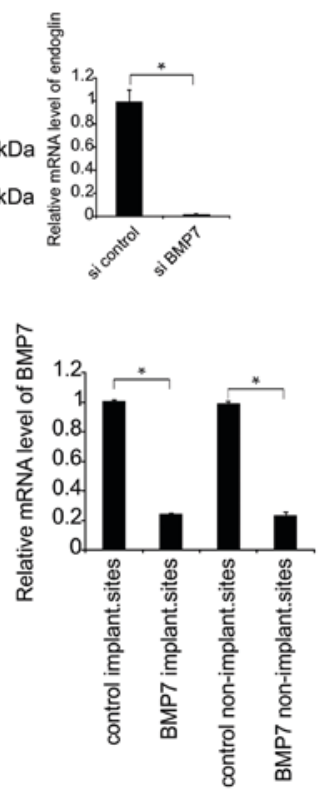

Figure 1. BMP7 regulates endoglin in endometrial epithelial cells during their receptivity. (A) BMP7 expression was analyzed in endometrial epithelial cells by western blotting. (B) Through immunofluorescence, the localization of BMP7 was determined with a confocal laser-scanning microscope in endometrial epithelial cells of mouse origin. (C) Silencing of BMP7 from endometrial epithelial cells was confirmed by western blotting. The expression level of endoglin was examined in response to BMP7 silencing in endometrial epithelial cells by western blotting. (D) Endoglin was detected by western blotting in endometrial tissue protein extract from the day $5,1000 \mathrm{~h}$ stage post-BMP7 silencing at day $4,1000 \mathrm{~h}$. (E) The transcript level of BMP7 was examined by reverse transcription-quantitative polymerase chain reaction in endometrial tissue at day $5(1000 \mathrm{~h})$ following BMP7 silencing. Data represent the mean \pm standard error of the mean of three independent experiments. "P<0.05. BMP, bone morphogenic protein; si, small interfering RNA.

Racl activation assay. Rac1 activation was analyzed using Rac1 Activation Assay kit (cat. no. ab211161; Abcam, Cambridge, MA, USA), according to the manufacturer's protocol. Briefly, protein extracts $(60 \mu \mathrm{g})$ were added to multi-well plates pre-coated with Rac-GTP-binding protein for $30 \mathrm{~min}$ at $4^{\circ} \mathrm{C}$. Following incubation, $50 \mu \mathrm{l}$ anti-RAC1 antibody was added to samples and incubated for $45 \mathrm{~min}$ at $4^{\circ} \mathrm{C}$. A total of $50 \mu \mathrm{l}$ HRP-conjugated secondary antibodies (Abcam) were added to samples and incubated for $45 \mathrm{~min}$ at $4^{\circ} \mathrm{C}$. A total of $50 \mu \mathrm{l} \mathrm{HRP}$ detection agent (Abcam) was added to samples for $20 \mathrm{~min}$ at $4^{\circ} \mathrm{C}$ for color development. The reaction was stopped by adding $50 \mu \mathrm{l}$ HRP halting solution (cat. no. ab211161; Abcam) and a microplate spectrophotometer was used to measure the optical density at a wavelength of $490 \mathrm{~nm}$.

Statistical analysis. All experiments were performed 3-5 times using different mice as replicates. Data presented as the mean \pm standard error of the mean. All statistical analyses were performed using GraphPad Prism software (version 6.0; GraphPad Software, Inc., La Jolla, CA, USA). Student's t-test was used to identify the significance of difference between two groups, and one-way analysis of variance followed by the Newman-Keuls test was used for multiple groups. The results of western blot band intensity are presented as a ratio (protein 
A

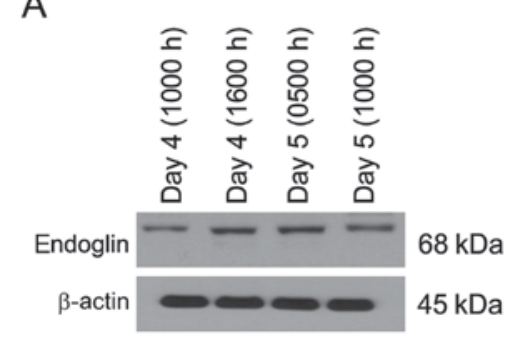

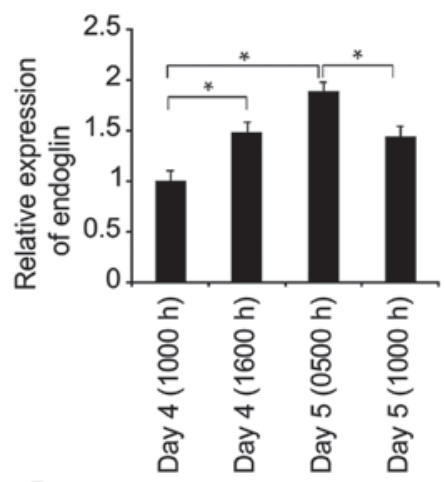

B
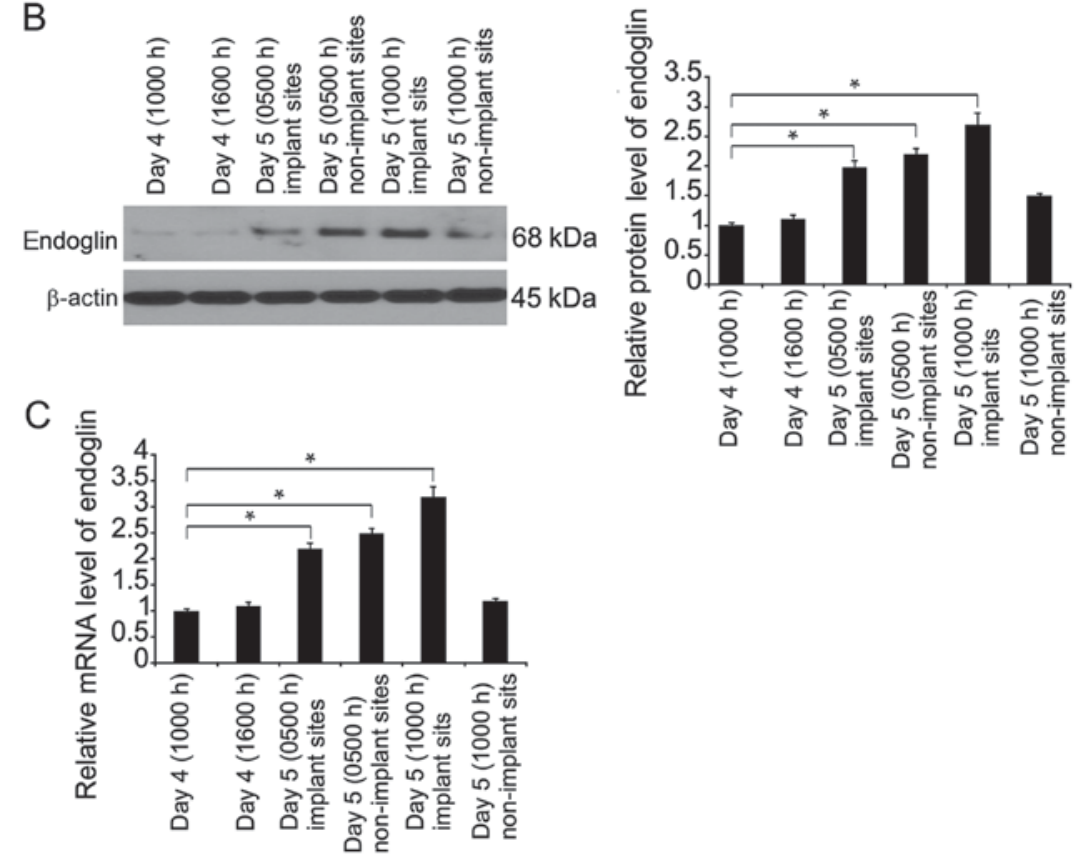

Figure 2. Endoglin expression was upregulated in the endometrium during the phases of receptivity for embryo implantation. (A) Endoglin was analyzed by western blotting in endometrial epithelial cells. (B) Endoglin expression was evaluated by western blotting in the endometrium during the endometrial (uterine) receptivity phases. (C) The transcript level of endoglin was also examined in the endometrium by reverse transcription-quantitative polymerase chain reaction during endometrial receptivity phases. Data represent the mean \pm standard error of the mean of three independent experiments. ${ }^{*}<<0.05$.

of interest $/ \beta$-actin) to correct for loading error for each sample. $\mathrm{P}<0.05$ was considered to indicate a statistically significant difference.

\section{Results}

BMP7 is upregulated at receptive status in endometrial epithelial cells during endometrial receptivity period in mice and mediates downstream pathway via endoglin. To evaluate the influence of BMP7 on embryo implantation, BMP7 was detected in endometrial epithelial cells during early gravidity (Fig. 1A). Prior to implantation, BMP7 expression was enhanced during the receptive period compared with its basal concentration in endometrial epithelial cells (Fig. 1A). At advanced stages following the receptivity period, BMP7 expression was generally decreased (Fig. 1A). BMP7 was expressed throughout the cells, but was most prevalent in vesicular compartments (Fig. 1B). To evaluate the interaction between endoglin and BMP7, BMP7 expression was silenced in endometrial epithelial cells, which resulted in a significant decrease in endoglin expression (Fig. 1C).

In vivo, BMP7 was knocked down via MO at 4 days, 1000 h. At 5 days (1000 h), BMP transcription was inhibited with or without implantation compared with in MO control, demonstrating BMP7 knockdown at day 5 at 1000 h (Fig. 1D). Endoglin expression was suppressed following BMP7 exhaustion in the uteri at day $5,1000 \mathrm{~h}$ stage (Fig. 1D). The expression of the tested factors (BMP-7, endoglin) was also determined in non-pregnant endometrium. The findings demonstrated that BMP7 is expressed in the endometrium during the early stages of pregnancy.

Endoglin is associated with endometrial epithelial cell preparation for receptivity construction. Endoglin has an essential role in embryo invasion, and its expression can be found in uteri luminal and glandular epithelium. It was revealed that BMP7 silencing led to suppression of endoglin expression in the endometria (Fig. 1D and E).

Subsequently, endoglin expression was evaluated by western blotting at different time points of endometrial receptivity in the uteri and separated endometrial epithelial cells acquired from receptive endometria. Primary endometrial epithelial cells subjected to separation and 24-h culture displayed slight elevations in endoglin expression during the period of receptivity or around implantation (Fig. 2A). Endoglin expression 

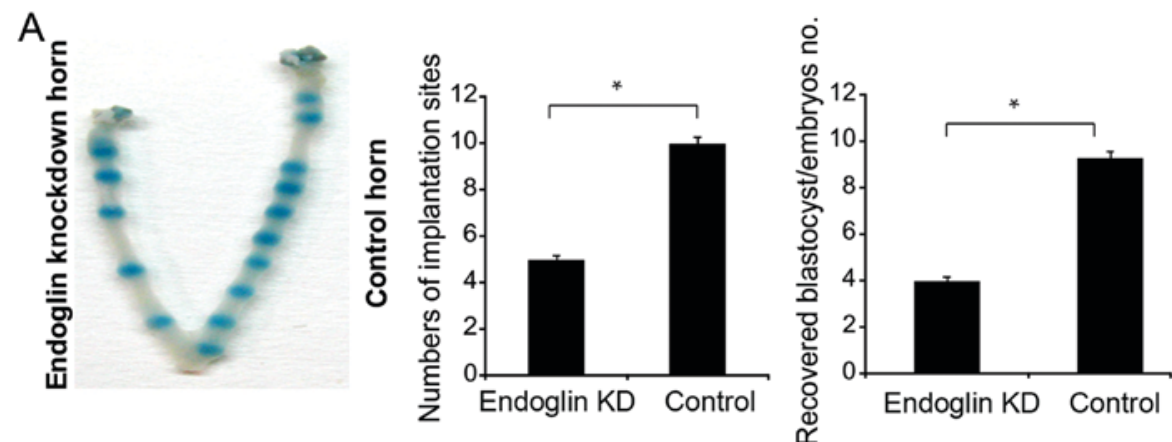

Day $5(1000 \mathrm{~h}) /$ post-receptive stage

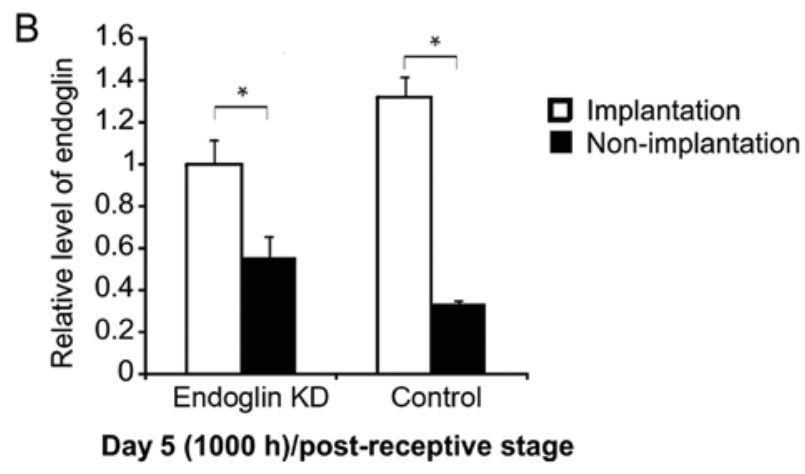

Figure 3. Endoglin inhibition causes poor implantation. (A) Endoglin inhibition during the pre-receptive stage of the endometrial receptivity period exhibited poor implantation and blastocyst numbers. (B) The expression level of endoglin was evaluated post-endoglin activity inhibition at day 5 (1000 h) in the endometrial tissue lysate. Data represent the mean \pm standard error of the mean of three independent experiments. " $\mathrm{P}<0.05$. KD, knockdown.

was examined in mouse uteri at different time points of endometrial receptivity. The results demonstrated that endoglin expression was limited prior to receptivity, but enhanced during and following receptivity (Fig. 2B and C).

Endoglin knockdown impaired implantation in mice. To evaluate endoglin activity in endometrial receptivity, endoglin was knocked down prior to implantation (day 4, $1000 \mathrm{~h}$ ) and cells were evaluated at day $5(1000 \mathrm{~h})$ following receptivity. The results revealed that implantation sites were decreased (Fig. 3A) and endoglin expression was unchanged at endoglin-suppressed implantation sites in the uterus (Fig. 3B); however, non-implantation sites were decreased in the two groups (Fig. 3B).

Racl-GTP is regulated via endoglin in endometrial epithelial cells during endometrial receptivity. As a G-protein belonging to the RHOGTPase family, Rac1 promotes endometrial receptivity and its suppression decreases embryo implantation (20). Previous studies demonstrated that Rac1 stimulation occurs via BMP7 in the renal epithelium (21).

Prior to examining the interaction between endoglin and BMP7, immunoprecipitation experiments were carried to determine the physical interactions between these proteins. Upon immunoprecipitation of BMP7, endoglin- as well as Racl-positive bands were detected (Fig. 4A). There were no bands for independent secondary antibodies (anti-mouse and anti-rabbit immunoglobulin G) on the immunoblots of endoglin, Rac1, or BMP7, suggesting an interaction between BMP7 and Rac1 as well as endoglin in the endometria to spread the BMP7 signals.
Racl activity was impaired when endoglin was exhausted in separated endometrial epithelial cells following 24-h culture from day 5 (0500 h; Fig. 4B). Furthermore, Rac1 expression was markedly suppressed when endoglin was exhausted (Fig. 4C). In vivo evaluation of endoglin regulation was carried out. Racl activity was inhibited when endoglin was exhausted at both implantation and non-implantation sites at day $5(1000 \mathrm{~h})$ compared with control implantation and non-implantation sites, respectively (Fig. 4D).

Racl-GTP is regulated via endoglin stimulator, BMP7, in endometrial epithelial cells. Next, Rac1 activity was determined using the Rac1 Activation Assay kit in endometrial epithelial cells at various periods of endometrial receptivity. Rac1 activity was enhanced at day $5(0500 \mathrm{~h})$ in endometrial epithelial cells (Fig. 5A). Rac1 stimulation was previously demonstrated to be regulated via BMP7 in mesangial cell-myofibroblast differentiation and stimulated via deactivating or separating RHOGDI, which suppresses Rac1 stimulation (21). Thus, BMP7 response to the activity of Rac1-GTP in endometrial epithelial cells and the uterus tissue was examined. Rac1-GTP levels were three-fold lower following BMP7 silencing in separated endometrial cells on day 5 (0500 h) (Fig. 5B). Rac1 expression was suppressed in BMP7 MO with or without implantation (Fig. 5C). The results also indicated that Rac1-GTP was suppressed in BMP7 MO with or without implantation (Fig. 5C).

Coculture of JAr spheroids following BMP7 knockdown/endoglin exhaustion in Ishikawa cell single layer revealed inhibited attachment. To assess blastocyst attachment modulated by 
A

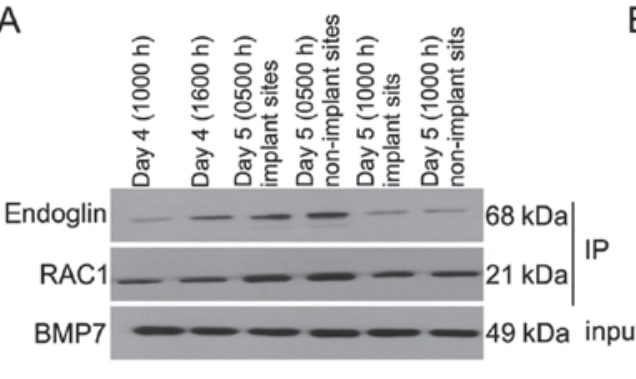

B

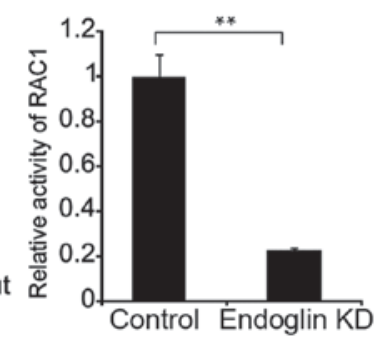

C

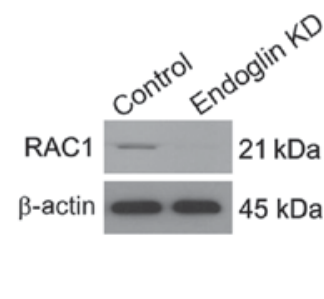

D
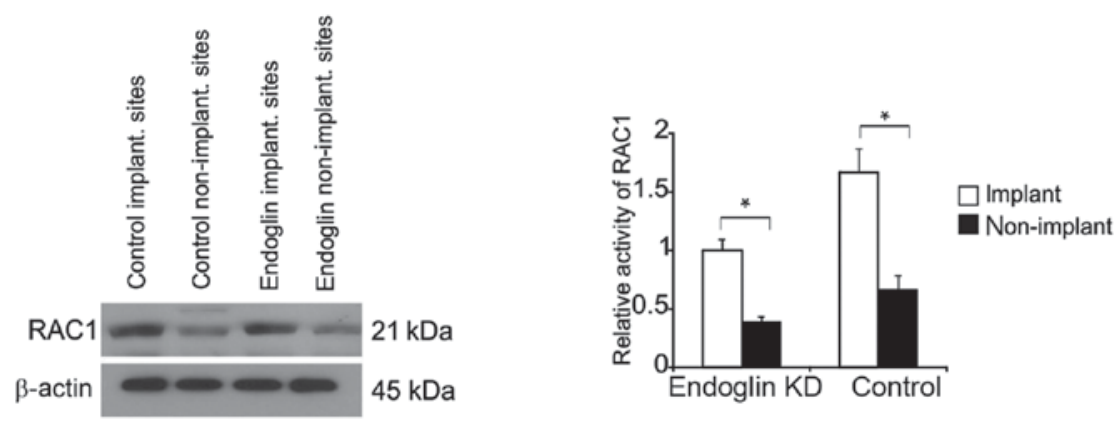

Figure 4. BMP7 formed a complex with endoglin and Rac1 in the endometrium and Rac1 is regulated by endoglin. (A) Endoglin was immunopositive on the immunoblot of BMP7 IP samples from endometrial tissue. Western blotting revealed the presence of Rac1 on IP samples of BMP7 from endometrial tissue proteins. (B) Rac1 activity was evaluated in endometrial epithelial cells from the day 5, $0500 \mathrm{~h}$ stage. (C) Expression level of Rac1 was determined in endometrial epithelial cells from the day $5(0500 \mathrm{~h})$ stage in response to endoglin inhibition. (D) In the endometrium, following endoglin inhibition, Rac1 expression and activity were analyzed at implantation and non-implantation sites in the post-receptive stage (day 5, $1000 \mathrm{~h}$ ). Data represent the mean \pm standard error of the mean of three independent experiments. ${ }^{*} \mathrm{P}<0.05 ;{ }^{* *} \mathrm{P}<0.01$. BMP, bone morphogenic protein; IP, immunoprecipitation.

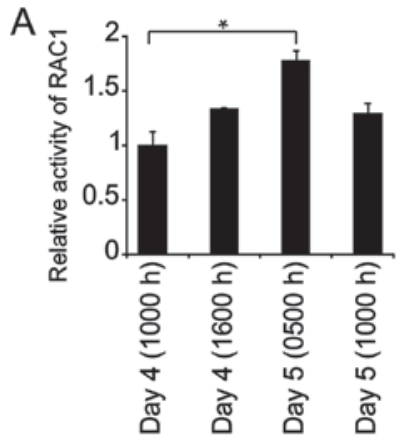

B

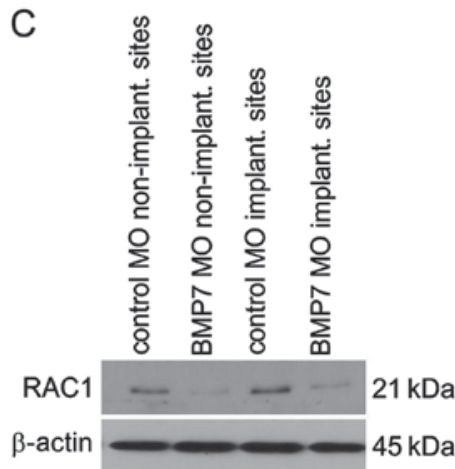

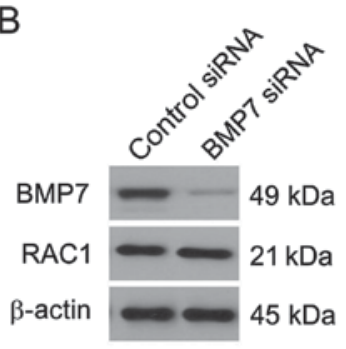
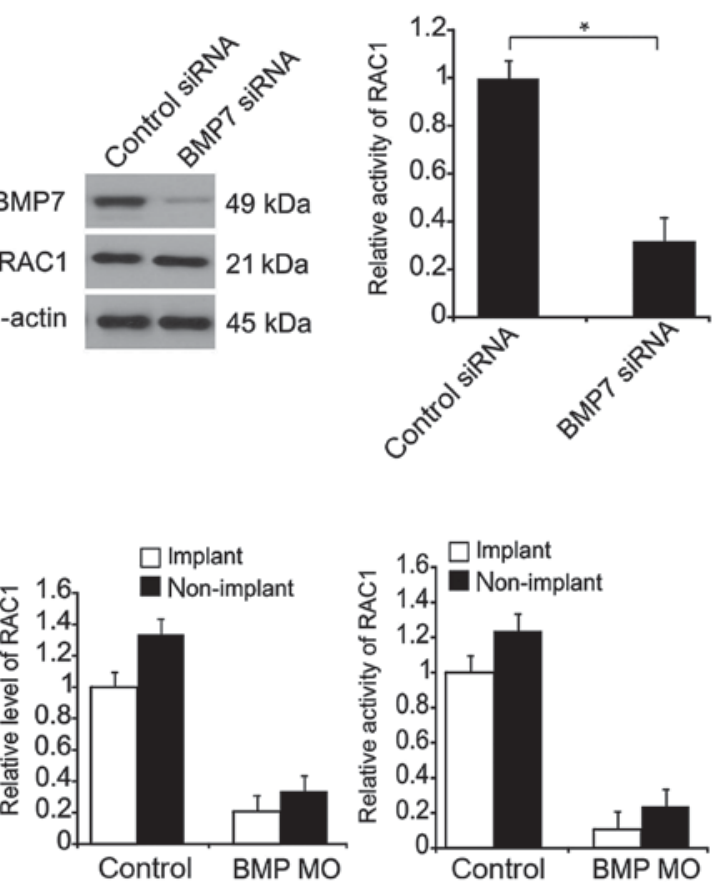

Figure 5. GTPRac1 is influenced by BMP7 in endometrial epithelial cells during endometrial receptivity. (A) Rac1 activity in the GTP-bound state was analyzed in isolated and cultured endometrial epithelial cells during various stages of the endometrial receptivity period. (B) Expression of Rac1 was assayed in endometrial epithelial cells following BMP7 knockdown by siRNA. (C) Expression of Rac1 and activity were determined in the whole uterus/endometrium during the post-receptivity phase in response to BMP7 knockdown. Data represent the mean \pm standard error of the mean of three independent experiments. ${ }^{*} \mathrm{P}<0.05$. BMP, bone morphogenic protein; siRNA, small interfering RNA; MO, Morpholino oligonucleotides.

endoglin or BMP7 on endometrial epithelial cells, spheroids served as embryonic bodies and were cocultured on a single layer of endometria. JAr spheroids $80-100 \mu \mathrm{m}$ in size were added to a single layer of Ishikawa cells in which BMP7 had been exhausted (siRNA; $60 \mathrm{nmol}$ ) or that had received transfection of scrambled siRNA. Coculture was conducted 


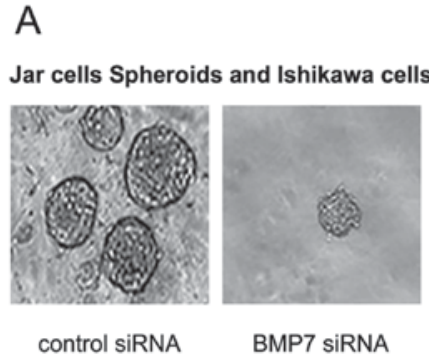

B

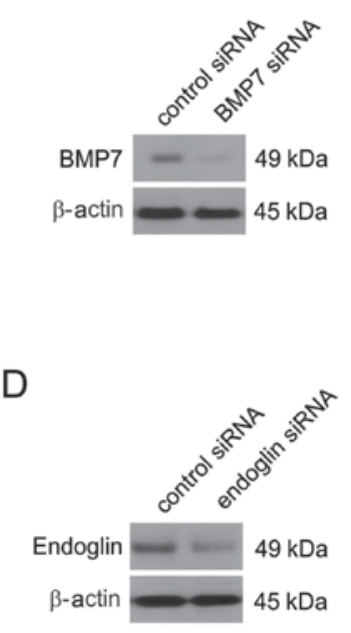

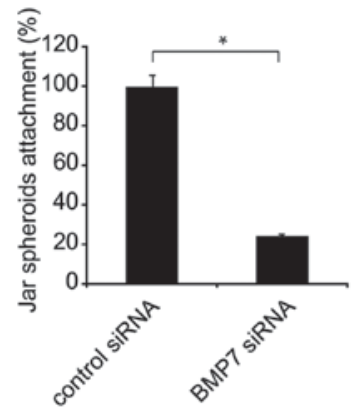

C

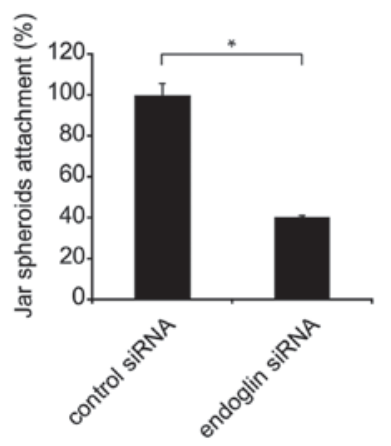

Figure 6. BMP7 and endoglin participate in blastocyst attachment reaction. (A) Attachment of human placenta origin JAr cell spheroids on endometrial epithelial cells (Ishikawa) was analyzed post-BMP7 silencing from endometrial cells and expressed as a percentage. The percentage spheroids adhered/attached was determined following 24-h incubation. (B) BMP7 knockdown efficiency was analyzed in Ishikawa cells by western blotting. (C) Following endoglin inhibition in Ishikawa cells, JAr cell spheroid attachment was analyzed and expressed as a percentage. (D) Endoglin levels were determined in Ishikawa cells post-endoglin inhibition by western blotting. Data represent the mean \pm standard error of the mean of three independent experiments. ${ }^{*}<0.05$. BMP, bone morphogenic protein; siRNA, small interfering RNA.

for $6 \mathrm{~h}$, and spheroid attachment was subsequently quantified ( $\mathrm{n}=3$; Fig. 6A). Attachment of spheroids cocultured with a single endometrial epithelial cell layer was inhibited when BMP7 was silenced (Fig. 6A). In total, $20 \%$ of spheroids were adhered (Fig. 6A). BMP7 knockdown was confirmed by western blotting in endometrial epithelial cells (Fig. 6B).

Additional experiments were conducted to examine co-culture of the Ishikawa layer with exhausted endoglin. Suppression of endoglin function reduced spheroid attachment by $\sim 60 \%$ (Fig. $6 \mathrm{C}$ ). Endoglin knockdown was confirmed by western blotting in endometrial epithelial cells (Fig. 6D).

\section{Discussion}

The present authors observed that BMP7 participates in endometrial receptivity during embryo implantation. The noticeable BMP7 expression in endometrial epithelial cells suggests its participation in the promotion of blastocyst attachment following the epithelium is processed for blastocyst attachment. BMP7 expression was promoted at day 5 (0500) during endometrial receptivity in endometrial epithelial cells, which modulates the receptivity of the epithelium as the receptive biomarkers were inhibited when BMP7 was silenced in endometrial epithelial cells. This suggests that BMP7 affects the endometrial receptivity status for the interaction and attachment of the blastocyst. This is supported by the fact that endometrial receptivity biomarkers are inhibited in recurrent miscarriage (22). The present study is the first to demonstrate that BMP7 is associated with receptivity of the endometrium. In addition, the results indicated that BMP7 regulates receptivity of endometrial epithelial cells for implantation of blastocysts via the endoglin pathway.

It was previously reported that mouse endometria expressing BMP2 and ALK2 failed to decidualize, leading to infertility (23). However, elimination of BMP7 only partly influenced natural gravidity (24) and did not affect artificial triggers of decidualization, indicating that BMP2 and extra ligands serve as primary targets of the TGF- $\beta$ group to promote decidualization (25). Additional studies are required to determine the influence of BMP7 on decidualization.

Downstream endoglin was demonstrated to be involved in endometrial receptivity for the adhesion of blastocysts (26). Endoglin stimulation in a reaction to BMP7 was identified in endometrial and endometrial epithelial cells in the endometrial receptivity stage. BMP7 interacts with endoglin, and upregulation of BMP7 during implantation may trigger endoglin migration to locations at the apex of uterine luminal epithelium to assist in promoting conditions for cross-talk between 
the endometrium and embryo (27). Thus, BMP7 may function in focal adhesions by increasing endometrial receptivity.

In addition to the interaction between BMP7 and endoglin, Rac1 stimulation occurs through BMP7. It has been demonstrated that Rac1 is necessary for endometrial receptivity (28). Rac1 stimulation was impaired when BMP7 was eliminated from endometrial epithelial cells in receptivity obtainment, demonstrating that Rac1 stimulation occurred via BMP7.

Reactions modulated by endoglin can assist in forming the loose structure of the luminal epithelium, making it less adhesive in the basal lamina and allowing for invasion of blastocysts (29). Endoglin concentration was highest at implantation sites during the endometrial receptivity period, resembling endoglin function in the endometrium. The separated and cultured endometrial epithelial cells reflected the influence observed in vivo, indicating that endoglin functions in endometrial receptivity or development, which was unexpected. Spreading of endoglin occurred mainly at the apex prior to receptivity and during the advanced period. The localization of endoglin returned to the basal areas of endometrial epithelial cells, which correlated with a previous study (30). Rac1 activity via endoglin modulation was detected in the entire uterus and endometrial epithelial cells in endometrial receptivity. Endoglin was stimulated by Rac1 signaling in reaction to BMP7.

In a recent study, defective junction remodeling as well as premature decline of the apical to basal polarity of the epithelium was observed when Rac1 was exhausted, disrupting endometrial receptivity and implantation (31). Rac1 was observed to function in endometrial epithelial cells regardless of endometrial receptivity status, but was greatest during implantation. The association between Racl and endometrial receptivity for implantation of blastocysts was examined. The results indicated that Racl activity was enhanced in implantation regions, revealing the function of Rac1 in the endometrium.

To achieve endometrial receptivity, BMP7 expression is based on 17- $\beta$-estradiol, as BMP7 transcription and translation is promoted by $17-\beta$-estradiol availability. Reactions in the glandular and luminal mouse epithelium are strongest towards $17-\beta$-estradiol. However, the BMP7 reaction in humans is distinct because adding estradiol and/or progesterone does not enhance BMP7 expression in Ishikawa cells; these cells are derived from carcinoma and cannot withstand normal conditions (32). Consequently, associating the reactions of Ishikawa cells with BMP expression in a mouse model is difficult. P4 enhanced the expression and activity of Rac1 in endometria of humans, indicating that Rac1 activity is regulated by available $\mathrm{P} 4$ to modulate endometrial receptivity, and thus Rac1 is promising for promoting receptivity (33).

In conclusion, the BMP7-endoglin-Rac1 axis functioned in endometrial epithelial cells to achieve receptivity to assist in blastocyst adhesion to construct gravidity. Additionally, the highest expression of BMP7 was observed in the presence of $17-\beta$-estradiol in endometrial receptivity specific to the epithelium during embryo implantation of mouse gravidity models. The present results indicated that BMP7 can be used as a biomarker to predict the endometrial epithelial cell receptivity for the attachment of blastocyst.

\section{Acknowledgements}

Not applicable.

\section{Funding}

No funding was received.

\section{Availability of data and materials}

All datasets used and/or analyzed during the current study are available from the corresponding author on reasonable request.

\section{Authors' contributions}

CY, XL, HS and BD designed the experiments; CY, LF and SS performed the experiments; $\mathrm{CY}$ and BD analyzed the data; BD prepared the manuscript. All authors read and approved the final manuscript.

\section{Ethics approval and consent to participate}

The present study was approved by the Ethics Committee of Qilu Hospital, Shandong University (Jinan, China).

\section{Patient consent for publication}

Not applicable.

\section{Competing interests}

The authors declare that they have no competing interests.

\section{References}

1. Yoshinaga K: Research on blastocyst implantation essential factors (BIEFs). Am J Reprod Immunol 63: 413-424, 2010.

2. Haouzi D and Hamamah S: The acquisition of the human endometrial receptivity phenotype: Lessons from proteomic studies. In: Reproductomics. Elsevier, pp303-314, 2018

3. Propst AM, Hansard L, Silverberg K, Hegtvedt M, Burger NZ and Vaughn TC: Endometrial receptivity and pregnancy rates are higher after 7 days of progesterone in medicated FET cycles. Fertil Steril 108: e357-e358, 2017.

4. Kumar V, Soni UK, Maurya VK, Singh K and Jha RK: Integrin beta8 (ITGB8) activates VAV-RAC1 signaling via FAK in the acquisition of endometrial epithelial cell receptivity for blastocyst implantation. Sci Rep 7: 1885, 2017.

5. Achache $\mathrm{H}$ and Revel A: Endometrial receptivity markers, the journey to successful embryo implantation. Hum Reprod Update 12: 731-746, 2006.

6. Aghajanova L, Hamilton AE and Giudice LC: Uterine receptivity to human embryonic implantation: Histology, biomarkers, and transcriptomics. Semin Cell Dev Biol 19: 204-211, 2008

7. Hill CR, Sanchez NS, Love JD, Arrieta JA, Hong CC, Brown CB, Austin AF and Barnett JV: BMP2 signals loss of epithelial character in epicardial cells but requires the Type III TGFbeta receptor to promote invasion. Cell Signal 24: 1012-1022, 2012.

8. Christensen ST, Morthorst SK, Mogensen JB and Pedersen LB: Primary cilia and coordination of receptor tyrosine kinase (RTK) and transforming growth factor $\beta$ (TGF- $\beta$ ) signaling. Cold Spring Harb Perspect Biol 9: pii: a028167, 2017.

9. Wang RN, Green J, Wang Z, Deng Y, Qiao M, Peabody M, Zhang Q, Ye J, Yan Z, Denduluri S, et al: Bone morphogenetic protein (BMP) signaling in development and human diseases. Genes Dis 1: 87-105, 2014. 
10. López-Rovira T, Chalaux E, Massagué J, Rosa JL and Ventura F: Direct binding of Smad1 and Smad4 to two distinct motifs mediates bone morphogenetic protein-specific transcriptional activation of Id1 gene. J Biol Chem 277: 3176-3185, 2002.

11. Frum $\mathrm{T}$ and Ralston A: Cell signaling and transcription factors regulating cell fate during formation of the mouse blastocyst. Trends Genet 31: 402-410, 2015.

12. Velasco S, Alvarez-Munoz P, Pericacho M, Dijke PT, Bernabéu C, López-Novoa JM and Rodríguez-Barbero A: L- and S-endoglin differentially modulate TGFbeta1 signaling mediated by ALK1 and ALK5 in L6E9 myoblasts. J Cell Sci 121: 913-919, 2008.

13. Lebrin F, Goumans MJ, Jonker L, Carvalho RL, Valdimarsdottir G, Thorikay M, Mummery C, Arthur HM and ten Dijke P: Endoglin promotes endothelial cell proliferation and TGF-beta/ALK1 signal transduction. EMBO J 23: 4018-4028, 2004.

14. Ruiz-Llorente L, Gallardo-Vara E, Rossi E, Smadja DM, Botella LM and Bernabeu C: Endoglin and alk1 as therapeutic targets for hereditary hemorrhagic telangiectasia. Expert Opin Ther Targets 21: 933-947, 2017.

15. Pece-Barbara N, Vera S, Kathirkamathamby K, Liebner S, Di Guglielmo GM, Dejana E, Wrana JL and Letarte M: Endoglin null endothelial cells proliferate faster and are more responsive to transforming growth factor betal with higher affinity receptors and an activated Alk1 pathway. J Biol Chem 280: 27800-27808, 2005.

16. Maurya VK, Jha RK, Kumar V, Joshi A, Chadchan S, Mohan JJ and Laloraya M: Transforming growth factor-beta 1 (TGF-B1) liberation from its latent complex during embryo implantation and its regulation by estradiol in mouse. Biol Reprod 89: 84, 2013

17. St-Jean G, Boyer A, Zamberlam G, Godin P, Paquet M and Boerboom D: Targeted ablation of Wnt4 and Wnt5a in Müllerian duct mesenchyme impedes endometrial gland development and causes partial Müllerian agenesis. Biol Reprod: Jul 13, 2018 (Epub ahead of print). doi: 10.1093/biolre/ioy160.

18. Richardson KA, Hannon PR, Johnson-Walker YJ, Myint MS, Flaws JA and Nowak RA: Di (2-ethylhexyl) phthalate (DEHP) alters proliferation and uterine gland numbers in the uteri of adult exposed mice. Reprod Toxicol 77: 70-79, 2018.

19. Livak KJ and Schmittgen TD: Analysis of relative gene expression data using real-time quantitative PCR and the 2(-Delta Delta C(T)) method. Methods 25: 402-408, 2001.

20. Leone DP, Srinivasan K, Brakebusch C and McConnell SK: The rho GTPase Racl is required for proliferation and survival of progenitors in the developing forebrain. Dev Neurobiol 70: 659-678, 2010.

21. Grijelmo C, Rodrigue C, Svrcek M, Bruyneel E, Hendrix A, de Wever O and Gespach C: Proinvasive activity of BMP-7 through SMAD4/src-independent and ERK/Rac/JNK-dependent signaling pathways in colon cancer cells. Cell Signal 19: 1722-1732, 2007.

22. Tan SY, Hang F, Purvarshi G, Li MQ, Meng DH and Huang LL: Decreased endometrial vascularity and receptivity in unexplained recurrent miscarriage patients during midluteal and early pregnancy phases. Taiwan J Obstet Gynecol 54: 522-526, 2015 .
23. Bollum LK, Huse K, Oksvold MP, Bai B, Hilden VI, Forfang L, Yoon SO, Wälchli S, Smeland EB and Myklebust JH: BMP-7 induces apoptosis in human germinal center B cells and is influenced by TGF- $\beta$ receptor type I ALK5. PLoS One 12: e0177188, 2017.

24. Akiyama I, Yoshino O, Osuga Y and Yano T: Bone morphogenetic protein-7(BMP-7) might contribute to folliculogenesis by promoting angiogenesis. Fertil Steril 98 (Suppl): S200, 2012.

25. Ying Y and Zhao GQ: Detection of multiple bone morphogenetic protein messenger ribonucleic acids and their signal transducer, Smad1, during mouse decidualization. Biol Reprod 63: 1781-1786, 2000.

26. Chadchan SB, Kumar V, Maurya VK, Soni UK and Jha RK: Endoglin (CD105) coordinates the process of endometrial receptivity for embryo implantation. Mol Cell Endocrinol 425: 69-83, 2016.

27. Monsivais D, Clementi C, Peng J, Fullerton PT Jr, Prunskaite-Hyyryläinen R, Vainio SJ and Matzuk MM: BMP7 induces uterine receptivity and blastocyst attachment. Endocrinology 158: 979-992, 2017.

28. Tu Z, Wang Q, Cui T, Wang J, Ran H, Bao H, Lu J, Wang B, Lydon JP, DeMayo F, et al: Uterine RAC1 via Pak1-ERM signaling directs normal luminal epithelial integrity conducive to on-time embryo implantation in mice. Cell Death Differ 23: 169-181, 2016.

29. Rossi E, Lopez-Novoa JM and Bernabeu C: Endoglin involvement in integrin-mediated cell adhesion as a putative pathogenic mechanism in hereditary hemorrhagic telangiectasia type 1 (HHT1). Front Genet 5: 457, 2014.

30. Chadchan SB, Kumar V, Maurya VK, Soni UK and Jha RK: Endoglin (CD105) coordinates the process of endometrial receptivity for embryo implantation. Mol Cell Endocrinol 425: 69-83, 2016

31. Ma Y, Zou H, Zhu XX, Pang J, Xu Q, Jin QY, Ding YH, Zhou B and Huang DS: Transforming growth factor $\beta$ : A potential biomarker and therapeutic target of ventricular remodeling. Oncotarget 8: 53780-53790, 2017.

32. Bradshaw FJ and Bradshaw D: Progesterone and reproduction in marsupials: A review. Gen Comp Endocrinol 170: 18-40, 2011.

33. Wang W, Ju YY, Zhou QX, Tang JX, Li M, Zhang L, Kang S, Chen ZG, Wang YJ, Ji H, et al: The Small GTPase racl contributes to extinction of aversive memories of drug withdrawal by facilitating $\mathrm{GABA}_{\mathrm{A}}$ receptor endocytosis in the vmPFC. J Neurosci 37: 7096-7110, 2017.

This work is licensed under a Creative Commons Attribution-NonCommercial-NoDerivatives 4.0 International (CC BY-NC-ND 4.0) License. 